\title{
Innovative Strategies of Agricultural Product Network Marketing under the Background of E-commerce
}

\author{
Yuan Fei \\ Business Administration Institute, Haikou College of Economics Haikou, 571127, China
}

Keywords: E-commerce; Agricultural products; Network marketing; Innovation

\begin{abstract}
.
Internet marketing is the use of Internet means to implement product sales. This marketing means, with a variety of characteristics such as openness, applicability and service, is not only an efficient and important marketing tool, but also an important core of enterprise product sales. E-commerce network marketing has low cost, strong interaction and other advantages, and can cover the whole world with the traffic advantage which attracts customers to participate in and reduces sales and maintenance costs. It is the most influential sales approach. The innovative strategies of agricultural product network marketing under the background of e-commerce are analyzed in this paper.

Internet marketing is a modern sales way, which makes use of computer communications and digital interactive media for product marketing. It increasingly becomes an important and key channel for product sales. Online shopping has become a popular trend. China has entered the electronic business age. Form E-commerce perspective, agricultural product network marketing should actively adopt innovative strategies to better develop China's agriculture and increase farmers' income.
\end{abstract}

\section{The significance of agricultural products' network marketing}

China's agricultural products’ network marketing significance is of two main factors.

The contradiction between supply and demand of agricultural products. China's agricultural products sales channels are now much unobstructed, and the contradiction between supply and demand between products highlights the inevitability and importance of network marketing implementation. The total value of China's agricultural output is gradually increasing in recent years, making a large gap between agricultural production and consumption, which exacerbates people's needs for food, fish, poultry eggs and other needs. The gap between production and demand becomes larger, which exacerbates structural contradictions [2]. Although there is still a large gap in China's domestic demand for products, many areas' agricultural products have not sold and farmers can only sell them in cheap price, which hinders the development of agricultural products. Supply and demand contradiction also hinders the increase in farmer's economic income. Agricultural industrialization and intensive management are affected. The blocked agricultural products flow information is the key reason for the emergence of such a contradiction and network marketing should be used to implement global coverage to solve this contradiction.

The network marketing environment of agricultural products is good. With the rapid development of China's social economy, information Internet technology has also made rapid development. Network costs are decreasing and the number of Internet users is increased significantly. The number of Internet users in rural areas is the fastest growing area, and the increasing number of Internet users and the reduced use cost of the network show that China's rural areas already have a good agricultural network marketing environment. Mobile terminals and software development are gradually introduced, and sales platform construction is developing along 
with the pace, making farmers more efficiently use sales platform for the sale of agricultural products, and thereby reducing sales and information flow costs. China is very supportive of the development of Internet of Things, accordingly also established three-dimensional logistics system. Agricultural products sales cold chain logistics difficulties promote China's logistics industry to be more professional and more sophisticated, which also broke through the bottleneck of agricultural products sales network and made agricultural network sales better development. Combined with the survey data, it can be concluded that China's future cold chain logistics industry will grow at a rate of $25 \%$ and the market size will exceed one trillion. Its market demand and market potential will achieve better development.

\section{The current situation of agricultural marketing network}

Internet penetration rate in rural areas is low. China Internet Center released a survey report on the development of rural Internet, which made a comparison of China's urban and rural Internet development and the gap, and analyzed that the gap in 2007 was $20.2 \%$, and in 2008 it expanded to $23.5 \%$, and $29.6 \%$ in 2009. Compared to that of town, rural Internet development is very slow, and urban and rural Internet gap is gradually expanding. The important basis for network marketing is the popularity of the Internet, so we should further improve rural Internet penetration.

Information infrastructure is relatively backward. With China's social and economic development, rural Internet infrastructure conditions have improved significantly, but some areas' network construction is still relatively poor. According to a relevant survey data analysis, $19.7 \%$ of rural people who do not access the Internet because there is no computer and people have no network access conditions accounted for 3.5\%. Farmers' family computer penetration rate is low in China's central and western rural areas because the economic development there is relatively backward. The development of agricultural information resources in different regions is poor and cannot more completely collect various types of agricultural information, so information utilization is low, and the information released cannot better meet the actual demand of farmers' personalization and localization. The resources distribution in agriculture-related websites is relatively scattered and the construction of agricultural information platform is also lagging behind, which cannot meet the farmers demand for information. The average annual income of rural residents in China is relatively low and the expenditure on information infrastructure construction is relatively low.

Farmers' Internet knowledge and information ability are poor. Some rural non-Internet users do not use Internet because they do not understand the computer and technology has become an important obstacle to the use of rural Internet. Rural residents Internet cognitive bias and network security and integrity issues will affect the farmers' application of network. Because agriculture is strongly seasonal and timely and the supply of agricultural products market is also changing with agricultural production seasons, especially for some fresh agricultural products, if not timely make procurement and sales, it will make farmers economic losses. We should actively carry out agricultural network marketing and further enhance farmers' Internet application knowledge level and information application ability.

Rural Internet business application rate is low. Rural farmers' cultural level is generally not high, and coupled with the impact of habits and values; the application of the network is very limited. Rural Internet users tend to be younger, low education people and students. Young people under the age of 19 account for $41.1 \%$, who are of low ratio engaging in agricultural production and sales. Rural business applications are still lagging behind and urban Internet users use business transactions network application significantly higher than that of rural users. Especially in online 
shopping and payment of business applications, urban use rate is significantly higher than the rural use rate, and rural network application content is mainly high entertainment network music and games, and network business application is low. We should further deepen and change rural Internet business application awareness. At the same time, agricultural products cannot be transmitted through the network, and must be passed through traditional logistics. Because agricultural products are relatively fresh and not easy to save, it is prone to rot moldy and get pests and diseases in the transport, storage and sales process, resulting in economic and material losses. Agricultural products sale should minimize circulation time with proper custody to reduce the adverse effects of agricultural marketing network.

\section{Agricultural marketing strategy innovation under e-commerce background}

Make use of the advantages of mobile e-commerce. Mobile e-commerce is mainly to use personal mobile processing terminals such as mobile phones, electronic equipment and technology in a high degree of integration for the implementation of mobile office, and provide people with more diverse services. Mobile terminal can also serve for personal banking, trading and entertainment. Compared with other equipment, it has better flexibility and convenience, and can effectively breakthrough equipment constraints for better real-time connection services and build a good network environment and reliable technology platform for agricultural marketing. The current difficulty of agricultural sales is that the flow of information is not smooth, which directly affects the sales of agricultural products. Agricultural sales are in a disadvantageous situation in rural areas because of limited hardware. Network is used to establish agricultural sales network, deal with various types of sales situation with fixed and mobile terminals, and give full play to various types of application services of equipment and site platform to promote better sales carryout of agricultural products. A lot of sites develop a series of sales personalized services which provides guidance and help for agricultural sales services and further enhances cooperation with the sites. This better solves intelligent retrieval and evaluation of agricultural product quality issues and promotes more agricultural products applicable network sales model. The use of mobile e-commerce better settles agricultural products difficulty problems, and it can highly integrate various types of information resources, process all kinds of sales information on mobile platforms, and build cooperation quality platform for farmers, agricultural products processing, and enterprises to better solve various needs. In addition, the use of such mobile terminals and telecom operators can also broaden business sales channels, such as building agricultural service platform, use WeChat, micro-blogging for exchanges with other experts and manufacturers, use B2C and C2C e-commerce platform to promote network transactions to promote the sale of agricultural products.

Take the advantages of Internet of Things. Agricultural products have a high seasonal and freshness demand, so agricultural logistics links should do a good job of cold storage work, which virtually increases the sales pressure and makes the supply chain management more complex, limiting farmers' expansion of market sales. The Internet of Things is the focus subject of China's construction and development and is developing very fast in recent years. Agricultural products should take advantage of Internet of Things to carry out network marketing, handle cold storage and transportation work, reduce the middle circulations, reduce product circulation chains, accelerate agricultural product sales rate, and improve the quality of agricultural products and better improve the current sales pattern. The development of Internet technology and electronic equipment has promoted the development of Internet of Things. Internet of Things is a big network, which can provide people with a variety of supply chain management and humanization services. Use the Internet of Things technology for trace-ability of agricultural products and make supply chain 
management more efficient and convenient. The integration of various types of Internet of Things technical solutions can also make a good integration and collection of physical supply to reduce the adverse effects of food safety accidents, especially to protect fresh agricultural products with circulation convenience and security. It lays a solid network marketing technical basis and provides a better network marketing development environment for efficient marketing of agricultural products.

Make use of good customer relationship advantage. In the process of agricultural products sale, customers play a vital role. If we can manage the customer relationship, we can occupy a good market share. So we should make more in-depth understanding of customer analysis. Based on customer attributes, needs and so on, implement various networks marketing program, and provide personalized service in order to improve customer trust, loyalty and dependence and reduce the phenomenon of loss of customers. Data mining in large data model is also conducive to customer relationship management. Many of our electricity business platforms have more customer data, which should be implemented data mining, and sum up the potential high-value information and knowledge, such as the analysis of different customers' group consumption characteristics, psychology and behavior. Sell to the platform customers with the use of pushing high-value information or customized way and make use of information to develop agricultural products sales strategy and production program. The relevant user data in data mining can also effectively improve the management relationship between customers. Make effective analysis of the inherent correlation between user data and develop appropriate marketing strategy for agricultural market sales needs and consumer groups' distribution. Make real-time monitoring of market price fluctuations and make adjustments to respond to achieve a better competitive advantage.

Enhance the training of agricultural products network marketing talents. Network marketing talents are the important guarantee and human support for the development of agricultural products network marketing. China's current agricultural products network sales talents are in short supply. Local governments at all levels should increase investment in rural vocational education and build a variety of rural vocational education and training institutions to provide farmers with knowledge and guidance in order to enhance farmers network, business and marketing management technology and effectively improve farmers' awareness of information and the use of information literature capacity. Train more technical personnel engaged in agricultural marketing network marketing to provide a solid human resources support for China's agricultural network marketing. Only by building talents, strengthening farmers' network information concept and making good use of network information resources can agricultural marketing work be better carried out.

\section{Conclusion}

Internet marketing carries out marketing activities with Internet information technology, which takes a new marketing model and concept of ideas and provides a broader marketing channel for agricultural marketing. Agricultural distributors can more fully and accurately grasp market demand information, and better reduce cost and operational risk. There are still some problems in network marketing of agricultural products in China, which need to be further reformed. In view of the actual analysis of the problems, corresponding reform and innovation measures are put forward.

\section{References}

[1] Du Nanlan. Agricultural marketing strategy under the perspective of E-commerce[J]. Economic Research Guide, 2015 (7): 55-55. 
[2] Sheng Fan. Agricultural marketing strategy innovative research under the background of E-commerce [J]. E-commerce, 2015 (7): 27-28.

[3] Zhou Zhengping, Ding Jiayun, Jiang Liuyi. Study on agricultural products international competitiveness based on network marketing [J] .Environmental Issues Exploration, 2013 (3): 148-152. 